\title{
COMPLEMENTARIDADE HIDRO EÓLICA: DESAFIOS E PERSPECTIVAS PARA O PLANEJAMENTO ENERGÉTICO NACIONAL
}

\author{
S. S. F. SILVA ${ }^{1 *}$, A. C. ALVES ${ }^{2}$, Â. M. C. Ramalho ${ }^{1,2}$, C. S. LACERDA ${ }^{1}$ e C. M. SOUSA ${ }^{2}$ \\ ${ }^{1}$ Universidade Federal de Campina Grande - UFCG \\ ${ }^{2}$ Universidade Estadual da Paraíba - UEPB \\ sandrasereide@yahoo.com.br
}

Artigo submetido em fevereiro/2014 e aceito em novembro/2015

DOI: $10.15628 /$ holos.2015.2006

\begin{abstract}
RESUMO
Estudos que retratam o cenário atual e as perspectivas futuras, envolvendo o tema planejamento energético no Brasil, têm lidado com a insegurança e a carência de informações sistematizadas. Diante desse enfoque, este estudo tem como objetivo geral analisar como a complementaridade hidro eólica é abordada no planejamento energético nacional, ressaltando suas perspectivas e desafios para nosso país e para a sociedade. Embasado numa revisão literária, pode-se afirmar que as fontes alternativas de energias renováveis exercem uma importante opção complementar ao atendimento do crescimento das necessidades do planejamento energético, tendo múltiplas vantagens ambientais, dentre as quais a redução potencial dos
\end{abstract}

gases responsáveis pelo efeito estufa na atmosfera. Constitui desafio de grande relevância a modificação no perfil da demanda energética, a ampliação da eficiência na produção e no uso final de energia e a transição de energias não renováveis em renováveis. Contudo, adverte-se que o alcance de uma matriz energética nacional limpa depende de ações integradas e pautadas no rigor do conceito de planejamento energético atrelado à incorporação de uma lógica sustentável, pois a asserção de que a matriz energética brasileira é limpa, devido ao uso de hidroelétricas, apresenta controvérsias socioeconômicas e ambientais, que podem conduzir a erros contínuos de planejamento e de políticas energéticas.

PALAVRAS-CHAVE: Energia renovável, Complementaridade energética, Planejamento energético

\section{COMPLEMENTARITY HIDROEÓLICA: CHALLENGES AND PROSPECTS FOR ENERGY PLANNING NATIONAL}

\begin{abstract}
Studies that describe the current situation and future, prospects involving energy planning in Brazil, has dealt with insecurity and lack of systematic information. Given this focus, the general objective of this study was to analyse how the complementarity of hydro and wind power is addressed in the national energy planning, highlighting its prospects and the challenges for our country and society. Based on a literature review, it can be stated that alternative renewable energy sources play an important additional role to meet the growing needs of energy planning and has multiple environmental advantages, including the potential reduction of gases that are responsible for the greenhouse effect in the
\end{abstract}

atmosphere. It is a challenge of great relevance the change in energy demand profile, the increase in production and end-use energy efficiency, and also the transition from non-renewable to renewable energy. Nevertheless, it is advised that the scope of a clean national energy matrix depends on integrated and guided actions that are in rigor at the concept of energy planning linked to incorporating a sustainable logic, since the assertion that the Brazilian energy matrix is clean, due to the use of hydroelectric, shows socio-economic and environmental controversy which can lead to continuous errors of planning and energy policies.

KEYWORDS: Renewable Energy. Complementarity Energy. Energy Planning. 


\section{APRESENTAÇÃO}

A partir do Século XVIII e, mais especificamente no Século XX, com a impulsão do desenvolvimento econômico, a competitividade entre os países, o avanço do crescimento populacional em escala exponencial, além da demanda global por energia elétrica que acompanhou os mesmos níveis de crescimento, tanto nas nações desenvolvidas quanto que estão em desenvolvimento, constatou-se um aumento significativo no uso dos recursos energéticos, sobretudo nos países capitalistas. Diante dessa conjuntura, em uma sociedade de risco global em face das crescentes explorações dos recursos energéticos é recorrente o debate acadêmicocientífico sobre a problemática, o que tem contribuído sobremaneira para ampliação de estudos sobre a temática, resultante, principalmente das inquietações da sociedade sobre a questão ambiental.

Neste contexto, a crise do petróleo ocorrida na década de 1970 pode ser considerada como um divisor estratégico da questão ambiental, implicando num repensar por parte dos estudiosos no que concerne aos conceitos de desenvolvimento dessas nações e, ao mesmo tempo questionando a forma de matriz energética predominante em alguns países no âmbito global. No entanto, Sachs (2007) afirma que não se pode responsabilizar a crise do petróleo pelo despertar para as questões ambientais, especificamente, as relacionadas ao setor energético mundial, pois o que de fato, a crise acarretou foi o despertar para uma nova tipologia de desenvolvimento. Um desenvolvimento do ponto de vista da sustentabilidade, em que foram conhecidos indicadores acerca de desastres ambientais, ocasionados pela emissão dos gases causadores de efeito estufa, que são disseminados na atmosfera pela vigente matriz energética. Especificamente nos combustíveis fósseis, como petróleo, carvão, termelétricas, cuja emissões são responsabilizadas, ao longo dos anos, pelo aquecimento gradativo do planeta e pelas grandes calamidades que têm ocorrido de maneira periódica e intensa nos últimos anos.

Adentrando-se nesse contexto, e tomando como base o cenário mundial de alterações climáticas, a questão energética é um dos enfoques da perspectiva da sustentabilidade, atualmente, tendo em vista a importância e crescimento das energias renováveis e das lacunas de planejamento energético nacional acerca das suas matrizes energéticas.

Neste sentido, Tolmasquim, Guerreiro e Gorini (2007), afirmam que a questão energética se mostra para o Brasil, a um só tempo, como um desafio e uma oportunidade. Desafio, do ponto de vista de que o desenvolvimento econômico e social demandará uma significativa quantidade de energia e com isso um alto grau de segurança e de sustentabilidade do setor energético. Sendo assim, a questão energética pode superar as expectativas de estrangulamento de abastecimento, e oportunidade pela prerrogativa do país poder planejar a sua matriz energética, empregando grandes quantidades de fontes primárias renováveis, pois existe uma vasta diversidade de alternativas energéticas a serem consideradas.

Com suas origens no próprio processo de planejamento empresarial, o planejamento energético surgiu com a meta principal de otimização da oferta de recursos energéticos, para o atendimento a uma demanda estimada por relações econométricas agregadas. Com isso, a possibilidade de substituição inter-energética, o aumento da eficiência energética e o gerenciamento pelo lado da demanda começam a dar origem ao que se denomina planejamento energético que pode ser conceituado como uma abordagem que coloca em um mesmo nível de 
decisão, alternativas de fornecimento de serviços energéticos, tanto pelo lado da oferta, quanto pelo lado da demanda (SWISHER; JANNUZZI; REDLINGER, 1997).

Em paralelo, para existir um eficaz planejamento energético nacional atrelado ao viés do desenvolvimento sustentável, faz-se importante o uso de fontes alternativas renováveis de energia como complementação às fontes tradicionais, tendo em vista que apenas as fontes tradicionais (fósseis) não possuem os requisitos necessários para se enquadrarem na definição de desenvolvimento sustentável. Para Brackmann (2009), as energias alternativas ou renováveis são quaisquer formas de energia cuja taxa de utilização seja inferior a taxa de renovação.

Ressalve-se que a ênfase ao enfoque energético, trazido para o debate sobre o meio ambiente e a diminuição dos recursos naturais, tem instigado a ciência e os representantes da sociedade a buscarem novas formas de gestão e de planejamento energético, tanto para os sistemas de geração de energia, quanto de transmissão e fornecimento. Isto porque a adoção de práticas de gestão e de planejamento energético para a sustentabilidade, que integrem de forma solidificada aspectos econômicos, sociais e ambientais têm sido, cada vez, mais recursivos no âmbito governamental e também empresarial e evidencia a apreensão dos governantes e das corporações com o futuro, representando um investimento em longo prazo.

Diante desses argumentos, estudos que retratam o cenário atual e as perspectivas futuras envolvendo o tema planejamento energético no Brasil tem encontrado a provocação de lidar com a insegurança e a carência de informações sistematizadas. Visando verificar essa abordagem, esta abordagem, este estudo tem como objetivo geral analisar como a complementaridade hidro eólica é abordada no planejamento energético nacional, ressaltando suas perspectivas e desafios para o país e para a sociedade.

Além deste item introdutório, o artigo apresenta na sequência: material e método de pesquisa utilizado, revisão teórica composta pela visão dos principais autores que tratam da temática em estudo, as considerações finais proferidas, bem como as referências bibliográficas consultadas para a realização deste estudo.

\section{MATERIAL E MÉTODOS}

O presente artigo é uma revisão literária, onde todos os dados sobre energia renovável (eólica), complementaridade energética, matriz energética nacional, planejamento energético e plano nacional de energia foram enfocados e analisados com base na literatura já existente.

\section{REVISÃO TEÓRICA}

No decorrer do texto abordar-se-á, à luz da visão dos autores pesquisados que as fontes alternativas de energias renováveis constituem uma importante opção complementar ao atendimento do crescimento das necessidades de demanda e oferta do insumo energia; e que quando se pensar em planejamento energético nacional, o conceito mais adequado deve ser o de complementaridade energética, pois o alcance de uma matriz energética nacional limpa depende do conceito de planejamento energético, atrelado ao respeito ao meio ambiente; e que a atribuição de que a matriz energética brasileira é limpa, devido ao uso de hidrelétricas, apresenta 
controvérsias socioeconômicas e ambientais, que podem conduzir a erros contínuos de planejamento e de políticas energéticas.

\subsection{Matriz Energética Brasileira}

De uma forma geral, matriz energética pode ser definida como sendo um conjunto de fontes diversas que ofertam internamente energia, ou mais exatamente, ser definida como sendo a oferta interna discriminada quanto às fontes e setores de consumo. Pode ser compreendida como um instrumento técnico que permite a um país acompanhar os resultados das políticas e estratégias setoriais implantadas, e revela de forma constante as respostas do mercado e da sociedade às opções encontradas.

Com base neste instrumento, pode-se ajustar o processo de planejamento do setor por meio, por exemplo, dos parâmetros de oferta e demanda, de maneira que a matriz energética propague os interesses da coletividade e conjeture as políticas e estratégias setoriais em andamento. Também, como instrumento técnico, o acompanhamento da evolução das fontes de energia existentes na matriz elétrica pode subsidiar a tomada de decisões no setor.

Neste sentido, os países que evoluem com sua matriz para recursos energéticos de custo e de impactos ambientais baixos alcançam importantes vantagens comparativas. Paradoxalmente, com o desenvolvimento econômico e social há uma significativa demanda de energia e com isso a necessidade de um alto grau de segurança e de sustentabilidade energéticas, muitas vezes gerando desagradáveis impactos ambientais (TOLMASQUIM; GUERREIRO; GORINI, 2007).

Conseguinte esse contexto, atualmente, vem sendo intenso o entendimento por parte dos estudiosos das teorias modernas acerca das questões ambientais, por ser uma das premissas da sustentabilidade econômica de um país e a sua habilidade de prover logística e energia para o desenvolvimento de sua produção, com segurança e em condições competitivas e ambientalmente sustentáveis.

Tolmasquim (2012), ao enfocar esse pensamento e ao relacionar com o contexto nacional, afirma que o Brasil tem feito seu "dever de casa" na área energética, tanto que é citado como referência internacional na produção de petróleo em águas profundas, na produção de etanol, no seu parque de geração hidrelétrico, no exponencial aproveitamento da energia eólica, no seu extenso e integrado sistema de transmissão de energia elétrica e, especialmente, na renovação de sua matriz tanto energética, quanto de produção de energia elétrica.

Diante deste argumento, permite-se elucidar, de acordo com as prerrogativas teóricas que a matriz elétrica brasileira possui, uma composição ímpar em relação ao resto do mundo com participação de geração hidroelétrica na ordem de $90 \%$. Esta participação é bastante expressiva para um mercado com a dimensão e escala do setor brasileiro. A matriz tem como base a existência de centrais hidroelétricas com grandes reservatórios que estocam água no período úmido do ano, permitindo a sua conversão em energia elétrica no período seco do ano. São estes reservatórios que possibilitam uma oferta regular de energia elétrica ao longo de todo ano mesmo com um regime hidrológico irregular.

No enfoque nacional, o Brasil encontra-se em uma situação privilegiada com relação ao mundo no que se refere ao aquecimento global e a questão energética. Enquanto no mundo, a produção e uso da energia são o grande vilão, no Brasil a energia pouco impacta as emissões de 
gases de efeito estufa (GEE). Confirmando esse enfoque, o Ministério das Minas e Energias (2012) comprova que $65 \%$ das emissões mundiais de GEE são decorrentes da produção e uso da energia, enquanto no Brasil esta participação cai para $16,5 \%$.

O mesmo Ministério também afirma que a participação da produção e do uso da energia no total de emissões de GEE nos EUA e na União Europeia representam $89 \%$ e 79\%, respectivamente. Isto decorre do fato de que a matriz energética brasileira é uma das mais renováveis do mundo. Enquanto a matriz mundial é apenas $13 \%$ renovável, a matriz brasileira é composta por $45 \%$ de fontes renováveis, o que coloca o Brasil em 17ạ posição no ranking mundial de emissões de GEE, ao passo que as emissões do setor energético de países como a China e os Estados Unidos são cerca de quinze vezes maiores que a brasileira (MME, 2012).

Ainda assim, advirta-se que no leilão de energia, ocorrido em dezembro de 2005, o Brasil começou a negligenciar a imagem "limpa" de sua matriz energética. Na ocasião, $70 \%$ da energia disponível foram vendidos para termelétricas movidas a combustíveis fósseis. As escolhas que serão tomadas no setor brasileiro de energia elétrica nos próximos 15 anos serão cruciais à segurança energética nacional, ao desenvolvimento econômico e social e à proteção ambiental do país. O Brasil é referência nas negociações internacionais sobre energias renováveis e mudanças do clima. Entretanto, se as decisões tomadas sobre o setor elétrico forem equivocadas, podem levar o país a colocar-se na contramão de acordos e esforços globais, tais como o Protocolo de Kyoto.

Contudo, afirma o MME (2012) que a situação do Brasil continua de forma expressiva no contexto global, uma vez que, na produção de energia elétrica, por conta da opção pela hidroeletricidade, a participação das renováveis é superior a $90 \%$, enquanto no mundo ela é de apenas $18 \%$. Esse grande percentual de fontes renováveis na matriz de energia elétrica nacional faz com que o Brasil esteja bem distante dos maiores emissores de GEE. Quando se observa o consumo e a produção de energia elétrica, o Brasil ocupa a 49a posição. O setor elétrico de países como a China e os Estados Unidos emite cerca de cem vezes mais que o brasileiro.

Conforme o Ministério de Minas e Energia (2011), a participação das fontes renováveis na oferta de energia brasileira, ao final de 2011 , era de $44 \%$. Ressalve-se que ocorreu uma pequena queda da parcela correspondente a essas fontes renováveis em relação a 2010, quando atingiram $45,2 \%$ da oferta energética. Tal diminuição refletiu a quebra de safra da cana-de-açúcar em 2011 (MME, 2012).

A quantidade de energia ofertada no Brasil em 2011 foi de 272,1 milhões de toneladas equivalentes de petróleo - TEP (MME, 2012), valor 40,3\% superior à de 2001, que foi de 193,9 TEP. Com isso, a participação relativa do petróleo na matriz energética brasileira vem regredindo nos últimos anos, passando de 45,4\% em 2001 para 39,1\% em 2011, o que representou uma queda de $14 \%$ no período. Em 2010, a principal destinação do petróleo consumo no país foi para o setor de transporte (53\%), seguido do consumo não energético (14\%) e do industrial (12\%), (EPE, 2011). Destaca-se, ainda, que o Brasil, em 2001, importava 22,5\% do que consumia em petróleo e derivados, enquanto, em 2010, sua produção foi 1,3\% superior ao consumo.

No que se refere à geração de energia elétrica no Brasil, há uma predominância das fontes renováveis, cuja participação foi de 85,6\%, em 2010 (MME, 2012). Advirta-se para tanto, segundo o MME (2012) o acréscimo de novas termelétricas a combustíveis fósseis até o ano de 2014, por já estarem contratadas por meio de leilões de energia já realizados. 
Ainda assim, as necessidades de energia têm sido providas preponderantemente, a partir da fonte hídrica, tendo em vista seu vasto potencial, um dos mais elevados do planeta. Entretanto, em algumas regiões brasileiras como, por exemplo, no Nordeste, o potencial hidrelétrico está quase esgotado. Neste sentido, dados do Instituto Brasileiro de Geografia e Estatística - IBGE (GWEC, 2010) demonstram que o consumo de energia elétrica na região Nordeste tem crescido em ritmo significativamente superior ao do PIB - Produto Interno Bruto regional. Enquanto o PIB do Nordeste cresceu no período de 1985 a 2008, à taxa média de 2,5\% ao ano, o consumo de energia elétrica evoluiu em média, 4,2\% a.a. Dentro desse contexto, e considerando o consumo de energia elétrica observado nesse subsistema, em 2008, correspondente a $54.252 \mathrm{GWh}$, depreende-se que em 2017 o consumo atingirá 85.510 GWh (MME, 2009).

Em face destes dados, permite-se afirmar que para suprir as necessidades futuras desse insumo, serão necessários significativos investimentos em acréscimo de capacidade instalada de geração e/ou de transmissão. Ante o iminente esgotamento da fonte hídrica no Nordeste, urge repensar saídas para atender à demanda crescente de energia elétrica na região.

É com embasamento nesse contexto que cada vez mais, tornou-se importante para os países o conhecimento de qual é a sua dependência de cada fonte de energia. Para tanto, usa-se o conceito de oferta de energia. A oferta de energia é a energia disponível aos consumidores. É a medida da produção, somada com a importação, tendo sido subtraída a exportação (CEMIG, 2012).

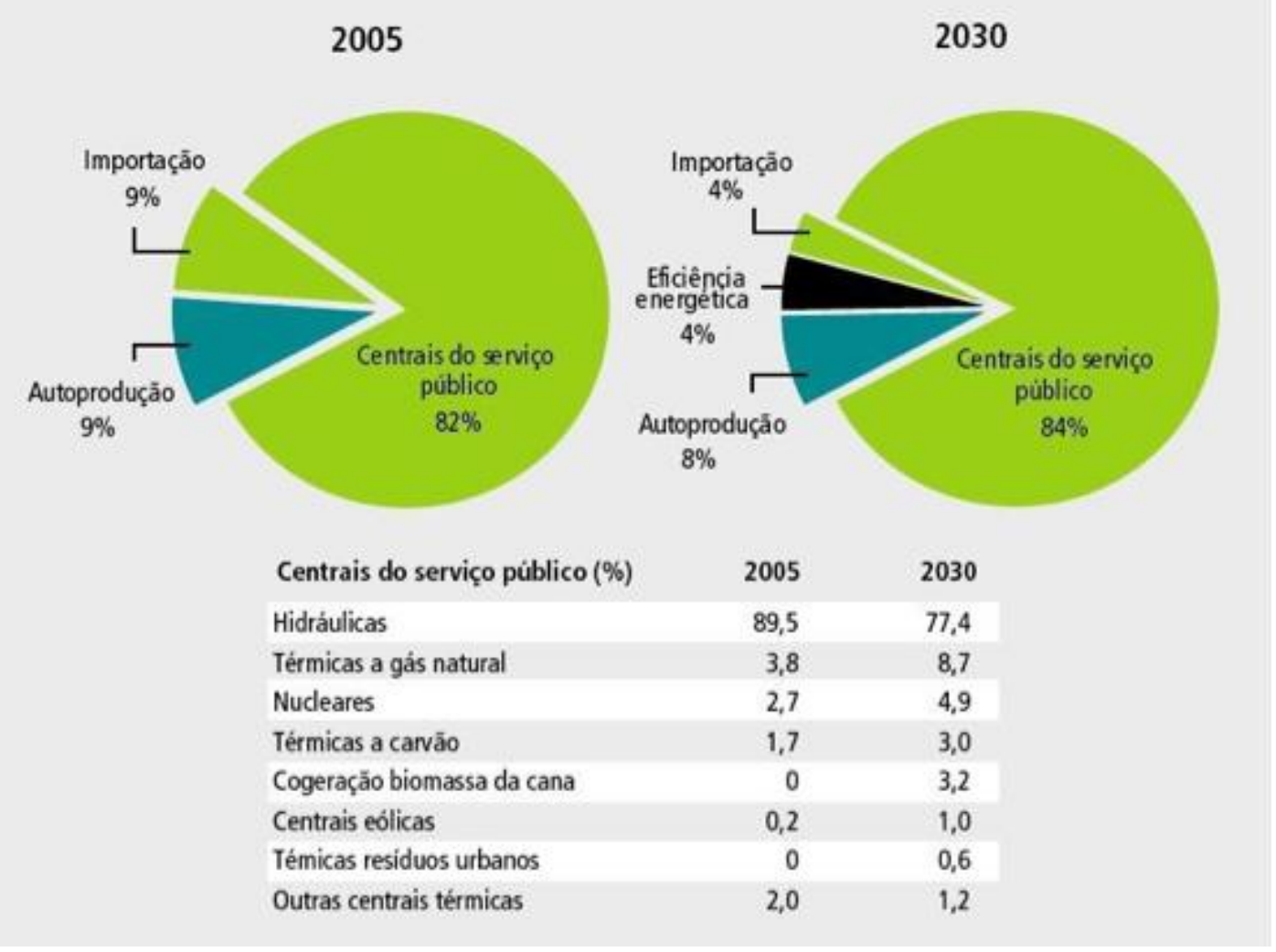

Gráfico 1 - Composição da matriz energética por tipo de geração em 2005 e expectativa para 2030. Fonte: EPE (2007).

A partir da quantificação da oferta, tem-se a matriz energética, que é a representação gráfica da oferta de energia. A importância de se construir e consultar a matriz energética de um país é estratégico. O conhecimento da matriz permite que sejam traçadas políticas energéticas 
nacionais, geralmente com o objetivo de tornar a matriz do país mais limpa e de diminuir a dependência externa da energia.

Neste ponto de vista, Reis, Fadigas e Carvalho (2005) enfatizam que a matriz energética de um País, Estado ou um dado local, em suas perspectivas de evolução ao longo do tempo pode ser definida como instrumento de fundamental relevância para a execução de um planejamento energético adequado. Advirta-se para o que tem sido considerado como diferença entre Matriz e Balanço Energéticos no Brasil. O Balanço Energético, apresentado anualmente pelo Ministério de Minas e Energia, configura a própria Matriz Energética do Brasil, contudo direcionada ao passado. No momento, o que se almeja é a construção de uma Matriz para o futuro.

No enfoque nacional, a análise das perspectivas de futuro da Matriz Energética é baseada no documento PNE 2030 elaborado pela EPE. As perspectivas de expansão da oferta de energia elétrica entre 2005 e 2030 são apresentadas no Gráfico 1, no qual se observa um aumento de 0,2\% para 1,0\% da participação das centrais eólicas na matriz energética nacional. Para atingir esse valor, o PNE 2030 (EPE, 2007) propõe analisar mecanismos de fomento às fontes alternativas renováveis de forma a aumentar a sua participação para mais de $4 \%$ na oferta interna de eletricidade.

De acordo com o cenário macroeconômico de referência, Tolmasquim, Guerreiro e Gorini (2007) tecem as seguintes considerações:

a) Em 2030 o consumo de energia elétrica no Brasil superará o patamar de 1.080 TWh, perfazendo uma expansão média de $4 \%$ ao ano no período considerado. Observe-se que essa projeção compreende uma parcela de eficiência energética referente ao progresso autônomo, isto é, ao aumento de eficiência decorrente de melhores práticas no uso e, sobretudo da progressiva substituição de equipamentos elétricos por outros mais eficientes nos diferentes segmentos da economia e da sociedade, incluindo avanços tecnológicos disponíveis no mercado. Admitindo-se a continuidade de tal tendência, essa conservação de energia responderia por cerca de $5 \%$ da demanda em 2030;

b) A estratégia de atendimento da demanda deverá considerar outras iniciativas na área de eficiência energética, que possam "suprir" mais uma parcela de cerca de $5 \%$ dessa demanda. Dessa forma, a condição de produção poderia ser reduzido para 1.030 TWh. A frustração dessa conservação suplementar sugeriria uma maior expansão da oferta, quantificada em 6.400 MW. Tendo em vista as eventuais limitações à expansão hidrelétrica, dadas pela classificação socioambiental, essa oferta adicional seria basicamente constituída por termelétricas ( $94 \%$, ou $6.000 \mathrm{MW}$ ). Ainda no campo da conservação, destaca-se do lado da oferta a possibilidade de redução das perdas totais, cujo índice, atualmente situado em quase $16 \%$, passaria a menos de $14 \%$ em 2030 ;

c) No que se refere à expansão da oferta, a geração hidrelétrica de grande porte mereceu uma abordagem específica, em virtude do fato de que aproximadamente $60 \%$ do potencial a aproveitar se concentra na bacia Amazônica, em grande parte ocupada por reservas florestais, parques nacionais e terras indígenas, de modo que a exploração desse potencial irá demandar estudos especiais acerca de sua sustentabilidade ambiental. Assim, os autores consideraram algumas restrições objetivas ao seu desenvolvimento (ainda que de um modo genérico) a fim de internalizar a questão ambiental; 
d) Considerou-se a priorização dos aproveitamentos hidrelétricos conforme o Plano Decenal de Energia Elétrica 2007-16, em elaboração pela EPE, e a priorização do desenvolvimento, nos próximos 25 anos, do potencial hidrelétrico das bacias hidrográficas indicadas pelo Ministério das Minas e Energia (MME), com apoio do Ministério do Meio Ambiente, com o objeto de estudos de avaliação ambiental integrada, bem como daquelas indicadas pelo MME como objeto de estudos de inventário e de viabilidade. Além disso, foram observados certos parâmetros referentes à interferência do projeto (usina e seu reservatório) em terras indígenas e em unidades de conservação de proteção integral e de uso sustentável. Tomou-se então como princípio geral retardar o aproveitamento avaliado como de maior complexidade ambiental. Antecipadamente, excluiu-se do horizonte do estudo uma parcela de $30 \%$ do potencial hidrelétrico nacional à guisa de impactos ambientais;

e) Nessas condições, avalia-se que a participação da energia hidráulica na oferta de eletricidade, da ordem de $90 \%$ em 2005 , cairia para pouco mais de $70 \%$ em 2030 . Já a geração térmica convencional (nuclear, a gás natural e a carvão mineral) expandiria sua participação de $7 \%$ para cerca de $15 \%$. As fontes renováveis (ou não-convencionais) não-hidráulicas (biomassa da cana, centrais eólicas e resíduos urbanos) também deverão experimentar crescimento expressivo, passando a responder por mais de $4 \%$ da oferta de eletricidade. Todas as formas de geração térmica irão se expandir mais de cinco vezes no período, aumentando o nível de emissões de gases na geração de energia elétrica. Essa é uma consequência natural de eventuais restrições ao desenvolvimento do potencial hidrelétrico brasileiro, não obstante a expansão que se possa admitir no parque gerador a partir de outras fontes renováveis;

f) Do lado da demanda, avalia-se que o setor industrial continuará sendo o principal segmento do consumo de eletricidade (42\% em 2030), mas deve-se destacar o crescimento tanto do setor terciário (quase $25 \%$ ) como do setor residencial (em torno de $26 \%$ ), refletindo as hipóteses de crescimento do nível de renda e de sua maior distribuição. Estima-se que o consumo de eletricidade residencial per capita, cujo índice atual é de apenas $38 \mathrm{kWh} / \mathrm{mês} / \mathrm{hab}$., possa chegar em 2030 a $99 \mathrm{kWh} / \mathrm{mês} / \mathrm{hab}$., que ainda é um valor bastante inferior aos parâmetros internacionais.

Diante destas considerações pontuadas, internaliza-se a importância que o Estado tem adotado no gerenciamento do setor energético, sobretudo, no que diz respeito aos entraves do mercado e a conflitos de interesses entre os vários agentes que ficam a frente desse setor.

Tolmasquim, Guerreiro e Gorini (2007) asseguram que essa estratégia vem sendo cultivada na intenção de minimizar os níveis de pobreza e ampliar o acesso à energia às camadas sociais menos favorecidas. Neste aspecto, outras ações também vêm sendo adotadas como métodos de minimizar os impactos ambientais, notadamente, a minimização dos gases e seus efeitos sobre o clima do planeta, o que tem reforçado a necessidade de regulação e da definição de políticas, especificamente orientadas para assegurar a sustentabilidade do desenvolvimento econômico, o que decerto exige planejamento e ação governamental.

Reis, Fadigas e Carvalho (2005) ao inferir acerca de estrutura de Matriz energética nacional de longo prazo, consideram três dimensões básicas de sustentação, sobre os quais deverá estar assentado o processo de tratamento da energia, com vistas ao planejamento de longo prazo. Essas 
dimensões estão relacionadas com o cenário energético atual e a necessidade de uma visão integrada, consistente e transparente da questão.

A primeira dimensão diz respeito à importância de integração da visão de planejamento com a do acompanhamento tecnológico e de fomento. Faz-se necessário a integração para a elaboração de cenários para planejamento aderente às políticas tecnológicas e de fomento com vistas a fornecer todas as informações precisas para análise e decisão.

A segunda dimensão refere-se à necessidade do estabelecimento de procedimentos para montagem de um sistema integrado, transparente e consistente de informações, com dados e modelos para simulação e análise. Tal sistema é essencial para a execução das tarefas visualizadas e, no enfoque global do setor energético, também deverá ser consistente com os requisitos de um banco geral de informações, necessário para a elaboração do planejamento integrado, do planejamento de longo prazo e dos planos decenais: eletricidade, dos combustíveis, da eficiência energética e das fontes renováveis.

Quanto à terceira dimensão, de suma importância, sobretudo no caso de estudos de longo prazo, é a necessidade de o planejamento apresentar características dinâmicas de avaliações periódicas congregadas a uma monitoração continuada do cenário de energia. Esse cenário apresenta forte efervescência, não apenas em termos nacionais, como em âmbito global, notadamente porque a questão ambiental tem sido cada vez mais influente e uma maior ênfase tem sido dada a uma adequada utilização de recursos naturais.

Em face dessas considerações e tendo como referência as três dimensões de sustentação e o cenário atual do planejamento de longo prazo, Reis, Fadigas e Carvalho (2005) apresentam algumas considerações e sugestões acerca da construção de uma matriz energética direcionada para o desenvolvimento sustentável:

a) Sobressai-se como requisito básico da estruturação de um processo para elaboração de cenários alternativos para a matriz energética, a necessidade de utilizar sinergia de todos os órgãos e instituições envolvidos, com as questões do planejamento. Devem-se estabelecer procedimentos direcionados a consolidar o processo de interação e integração entre os grupos do governo (ministérios e outros) e órgãos e instituições do setor elétrico voltado ao planejamento (pesquisa de mercado e balanço de oferta, políticas tecnológicas, industriais e energéticas; fomento nacional e internacional; pesquisas entre outros);

b) Na criação de cenários alternativos para o próximo período de vinte anos, associados a políticas tecnológicas e de fomento (ressalvem-se aquelas direcionadas ao incentivo de utilização das fontes renováveis, da eficiência energética e das tecnologias ambientalmente adequadas), deverão ser consideradas não só as políticas já estabelecidas e em andamento, mas outras como a experiência mundial (adaptada às condições do Brasil) em políticas similares e outras políticas que possam advir ou serem sugeridas, em função da evolução da questão ambiental, em âmbito nacional e global;

c) Deverão ser estabelecidos procedimentos e metodologias para atualização das informações, elaboração de previsões, acompanhamento (monitoração) e avaliação (realimentação) das informações, considerando, dentre outros, para as diversas fontes; geração de energia elétrica; co-geração; outros usos energéticos; geração distribuída; 
questão ambiental (relações e oportunidades internacionais); questão tecnológica e de fomento; e políticas em andamento e sugeridas;

d) Deverão ser estabelecidos procedimentos para a compatibilização, consistência e integração das informações, dados e modelos para simulação e análise, disponíveis e em uso no país, com vistas a estabelecer uma estrutura de informações, dados e modelos para simulação e análise, disponíveis e em uso no país, com vistas a estabelecer uma estrutura de informações, dados e modelagem integrada, consistente e georeferenciada, que deverá atender aos requisitos de um sistema maior, de todo o setor energético.

Com base nas considerações pontuadas, um conhecimento adequado da Matriz Energética, desde a prospecção de recursos até os diversos usos finais, bem como a participação de todos os envolvidos nas discussões, no acesso e na necessidade de participar do sistema de informações dentre outros, poderá permitir a discussão e sugestão de políticas específicas para determinado setor e um dado recurso natural.

Necessário também se faz prospectar sempre a longo prazo as políticas internacionais, notadamente, as que podem originar oportunidades para países como o Brasil, identificando tendências e subsídios que possibilitem nortear a definição de políticas públicas direcionadas a garantir uma disponibilidade energética adequada e em conformidade com os princípios de desenvolvimento sustentável. Para tanto, conhecer os desafios do setor energético, a formatação de um instrumento, com base em metodologia consistente que possibilite comparar empreendimentos de fontes de geração distintas e as bases para um planejamento energético direcionado para o desenvolvimento sustentável, mostra-se como importante passo no melhor posicionamento no novo cenário energético internacional.

Neste enfoque, deverão ser geradas novas alterações internas de caráter competitivo e também gerencial, fazendo-se necessário o estabelecimento de novos processos e procedimentos que possibilitem essa avaliação conjunta da energia com outras utilizações de recursos, tais como aqueles que compõem a infraestrutura para o desenvolvimento sustentável, especialmente as fontes renováveis de energia, dentre as quais a energia eólica, tendo em vista que o custo "zero" de seu combustível (ventos), reduzido custo de manutenção, resumido espaço de tempo necessário para sua instalação e operação, dentre outros fatores, vêm solidificando o espaço da energia eólica dentre as demais fontes de energias renováveis na construção de uma matriz energética mais diversificada e em busca da sustentabilidade no longo prazo.

\subsection{Energia Renovável (Eólica) e Complementaridade Energética}

As apreensões levantadas com a crise do petróleo e com o aquecimento global levaram o mundo a despertar para métodos alternativos de produção de energia. As menores emissões de gás carbônico apresentadas por essas alternativas e o fato de serem renováveis são ecologicamente atraentes na atualidade. Além disso, a minimização da dependência das fontes fósseis, notadamente, dos países onde estão suas reservas - é uma perspectiva importante, que justifica o investimento nas fontes alternativas de energia.

Conforme Dutra (2007), o desenvolvimento das formas alternativas de energia - FAE de geração renovável, observada ao longo das décadas de 1980 e 1990, demonstra que a aplicação de políticas específicas no setor energético determinou de maneira decisiva o sucesso ou o fracasso 
da aplicação dessas fontes na geração de energia elétrica. Questões como os impactos ao meio ambiente e o aquecimento global geraram uma necessidade de mudanças na geração elétrica em vários países do mundo (DUTRA, 2007). Muitos desses países estipularam metas e definiram programas com o objetivo de criação de um ambiente mais favorável para a que as FAEs de geração renovável pudessem ter uma participação mais efetiva na matriz de geração de energia elétrica, reduzindo também a dependência de combustíveis fósseis.

Esses fatores fizeram com que diversos países não só regulamentassem a utilização das fontes alternativas, como também criassem políticas de incentivo ao desenvolvimento e à produção das alternativas energéticas renováveis. Nesse sentido, Reis, Fadigas e Carvalho (2005) chamam a atenção para a geração eólica e afirmam que esta não é uma nova descoberta; é uma das formas mais primordiais de geração de energia renovável e que vem sendo utilizada há milhares de anos, contudo, é uma das alternativas energéticas de geração de eletricidade com perspectivas de gerar quantidades substanciais de energia.

Diferentemente de uma usina hidrelétrica ou nuclear, a usina eólica não apresenta perigo de vazamento de combustível. Em virtude disso, o mercado de energia eólica é o que cresce mais rápido dentre as chamadas fontes alternativas de energia. A capacidade eólica mundial atingiu 121 GW em 2008, superando a estimativa de 115 GW realizada pelo GWEC em 2007. Com essa nova capacidade, o planeta evita, anualmente, a emissão de cerca de 158 milhões de toneladas de $\mathrm{CO}_{2}$ na atmosfera. Atualmente, sua principal função é gerar eletricidade em escala comercial, cumprindo um papel de destaque no sentido de reduzir as emissões globais de gases de efeito estufa (GEE), e também de minimizar a dependência da geração elétrica, a partir de combustíveis fósseis, uma vez que estes são não renováveis e poluentes (IPCC, 2011; DUTRA, 2007).

Quanto à capacidade cumulativa instalada de produção global de energia eólica de 1996 a 2010 segundo dados da Global Wind Energy Council (GWEC) é apresentada a seguir:

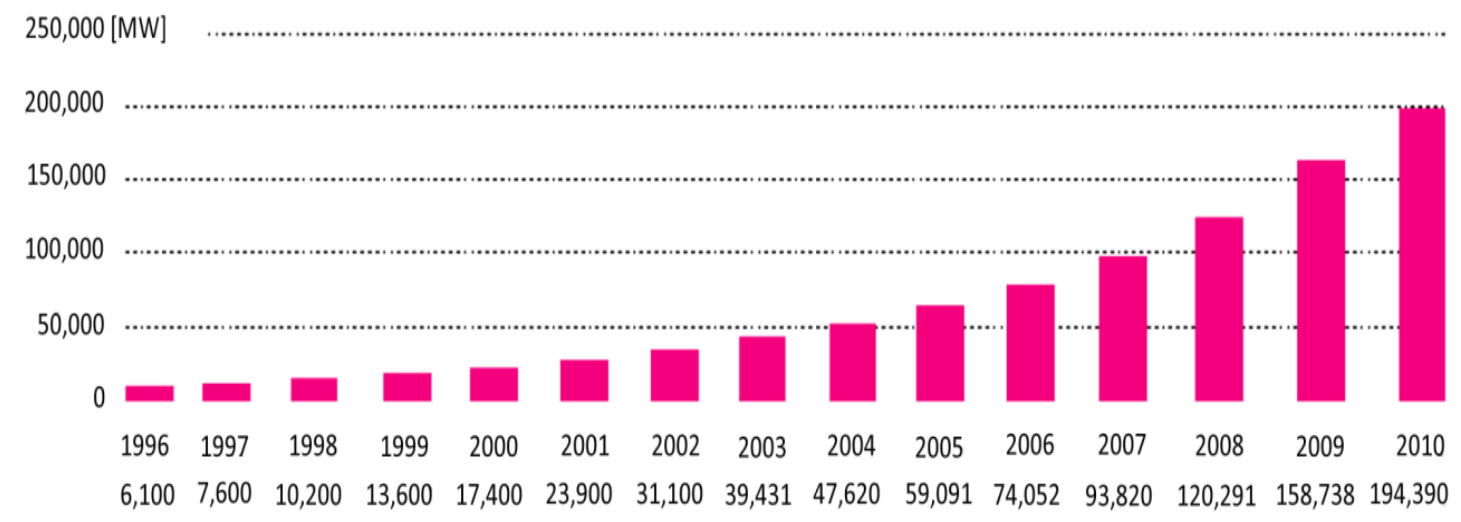

Figura 1 - Capacidade cumulativa de produção global de energia eólica. Fonte: GWEC (2010) e Nascimento, Mendonça e Cunha (2012).

Os dados apresentados evidenciam a tendência de crescimento do setor ao longo do período de 15 anos. Essa tendência de crescimento pode ser alvo de análises para o desenvolvimento de políticas setoriais específicas para os países com interesse no desenvolvimento das tecnologias envolvendo esse tipo de produção de energia (JUNFENG et al., 2006).

Segundo estimativa do World Wind Energy Association (WWEA), a capacidade eólica mundial instalada chegará a 190 GW em 2010 e 240 GW em 2012, o que corresponderia a 3\% da 
produção total de eletricidade. A Europa concentra mais da metade da capacidade eólica instalada mundialmente, seguida da América do Norte e da Ásia. As demais regiões têm participação reduzida, respondendo conjuntamente por menos de 2,5\% da capacidade eólica global. Programas energéticos na América do Norte e na Ásia vêm incentivando a instalação de imensos parques eólicos anualmente, de forma que a Europa, pela primeira vez em 2008, deixou de ser a região líder em incremento de capacidade. Há uma aposta grande no aumento da capacidade eólica offshore, que ainda é tímida, totalizando apenas $1 \mathrm{GW}$ no mundo.

Os dados demonstram que em 2010 esse valor foi 11 vezes maior e, segundo EPE (2011), 49\% dessa capacidade estará concentrada na Alemanha. Essa tecnologia está prestes a se tornar economicamente viável para competir com as fontes tradicionais de geração de eletricidade em países como Alemanha, Dinamarca, EUA, e mais recentemente na Espanha, entre outros. Além disso, é grande o potencial eólico a ser explorado em diversos países.

No caso dos países emergentes, Abramowski e Posorski (2000) afirmam que estes têm apresentado alto potencial de produção de energia eólica, mas enfrentam barreiras decorrentes de falta de experiência, carência de recursos, atrasos tecnológicos e métodos para seleção dos locais adequados para implantação das turbinas de captação e transformação de energia cinética em eletricidade, o que corresponde a um cenário expressivamente diferente do enfrentado por países desenvolvidos. Todavia, existem oportunidades de melhoramentos tecnológicos, bem identificados internacionalmente, que devem levar a reduções de custo e permitem estabelecer metas bastante ambiciosas para instalação de sistemas de geração nos próximos 30 anos.

No Brasil, particularmente na região Nordeste, uma das vantagens da energia eólica é sua complementação à modalidade hidrelétrica nas regiões atingidas pelas secas. Exemplo dessa situação é a Região Nordeste no Brasil que, em períodos de seca, os ventos são mais favoráveis, especificamente durante o período do segundo semestre de cada ano; é o que Bittencourt, Amarante e Schultz (1999) denominam de complementaridade entre a oferta de eletricidade de fonte eólica e hídrica no Nordeste do Brasil.

Isto acontece, segundo os autores supracitados, porque a convergência de estabilização sazonal na oferta de eletricidade de fonte eólica como complemento tem sido evidenciada ao longo dos anos ao serem estudados os níveis médios de vazão dos rios, atendendo a algumas plantas geradoras da região Nordeste e da região Sul. A velocidade do vento costuma ser maior em períodos que coincidem com baixas precipitações, o que possibilita operar as usinas eólicas de forma complementar às hidrelétricas, contribuindo para preservar a água dos reservatórios nos períodos de estiagem. O período em que ocorre a menor vazão dos rios é aquele no qual existem as maiores incidências de vento. A imprevisibilidade dos ventos não pode ser levantada como argumento inviabilizador da expansão da capacidade eólica no mundo; isto porque, essa fonte não deve ser usada como exclusiva na matriz de uma região. O correto é compreender a energia eólica como uma fonte coexistente e complementar às demais disponíveis.

Advirta-se que, diante desse cenário de possibilidades, algumas iniciativas no Nordeste do Brasil para instalação de energia eólica atrelada à rede de difusão, as E-FERs tiveram seu uso limitado à pesquisa, desenvolvimento e demonstração de projetos pilotos para eletrificação de comunidades rurais e isoladas, onde as grandes distâncias impossibilitavam o alcance da rede de energia elétrica. Contudo, o grande diferencial para o setor configurou-se no ano de 2002, do ponto de vista das políticas públicas, com a aprovação da Lei 10.438 que instituiu o PROINFA, 
determinando metas para a participação das fontes de energia renovável no sistema interligado nacional.

De acordo com a Figura 2, percebe-se que a complementaridade na geração de eletricidade tem se mostrado uma temática de grande importância, uma vez que, de acordo com o Balanço Energético Nacional (MME, 2005), a demanda de eletricidade no Brasil aumenta em torno de 5\% ao ano. O crescimento da demanda e a procura por novas fontes geradoras de energia mostramse como desafios presentes no setor elétrico, fazendo com que a eletricidade de fonte eólica seja uma opção cada vez mais atual nos novos projetos de geração e expansão do setor elétrico brasileiro.

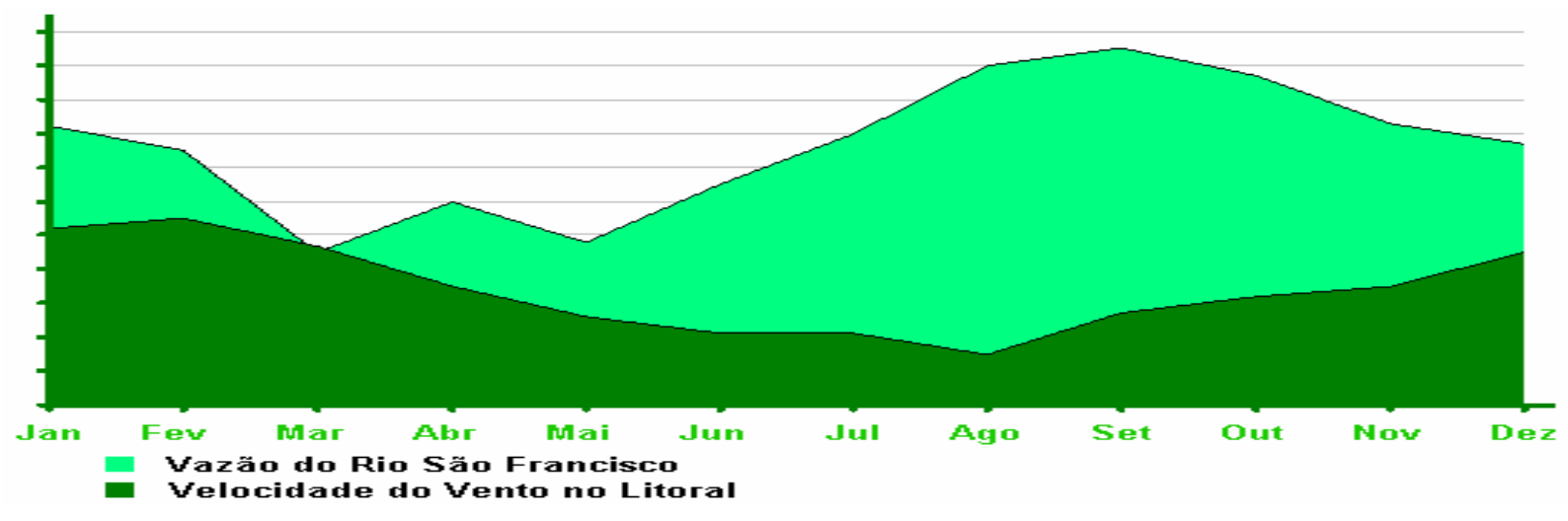

Figura 2 - Complementaridade dos regimes eólico e fluvial no Nordeste. Fonte: Adaptada de CBEE (apud FRATE, 2006).

É neste cenário do ponto de vista macroeconômico que já se estabelecem as tentativas locais de desenvolvimento sustentável, a partir da integração da matriz energética vigente ao uso sustentável das energias renováveis. Outro aspecto positivo da energia eólica é sua não vulnerabilidade a pressões políticas e econômicas, como o gás natural e o petróleo. Nesse aspecto, diversos países vêm investindo na complementação e transformação de seus parques energéticos com a introdução de fontes alternativas de energia. As questões ambientais alavancaram em muito estes investimentos, sobretudo, devido aos impactos causados pelas formas tradicionais de geração de energia.

De acordo com a ANEEL (2012), existem 73 usinas eólicas em operação no país, que possuem uma capacidade instalada total de $1.576 \mathrm{MW}$. Entretanto, estão em construção outros 59 empreendimentos que, juntos, alcançam $1.507 \mathrm{MW}$, o que permitirá dobrar a capacidade instalada em pouco tempo. O número de usinas eólicas outorgadas, mas que ainda não iniciaram a construção chega a 180, com uma potência total prevista de $5.207 \mathrm{MW}$. Percebe-se nessa explanação, a existência de uma interessante alternativa de complementaridade ao sistema elétrico que se apresenta ao país. A progressão da presença da fonte eólica no parque de geração de eletricidade do Brasil nos anos 2009 e particularmente em 2010 foi destacável comparada com a evolução experimentada nos anos 2002-2008.

No âmbito nacional, a produção, em 2010, de 2,18 TWh, representou apenas 0,4\% da oferta interna de eletricidade naquele ano. Entretanto, em relação a 2009, o crescimento foi de $76 \%$ (ANEEL, 2011).

Observando-se a configuração atual da matriz energética no Brasil, cabe ressaltar que as cifras de implantação que refletem a tecnologia eólica sugerem uma tendência de progressivo e 
rápido crescimento, em particular no que se pese sobre as magnitudes de potência elétrica em construção entre as diferentes tecnologias.

As magnitudes de potência eólica representadas no Gráfico 1 suscitam várias reflexões, dentre elas, destaca-se o incremento de potência instalada que haverá de acontecer nos próximos exercícios, quando em 2011, praticamente triplicou a potência instalada com respeito à registrada em 2010, em maior medida, o incremento de potência instalada que deve acontecer ao longo do próximo exercício de 2012, onde esse aumento significa mais que sextuplicar a referida capacidade, de maneira similar ao que também deverá acontecer em 2014.

Percebe-se que apesar de o setor energético ter se modificado muito nas últimas décadas, ainda deverá passar por grandes mudanças num futuro próximo, não só em decorrência da demanda ambiental e das alterações de mercado, mas, principalmente, em virtude das novas políticas públicas redirecionadas para o desenvolvimento tecnológico do setor.

Corroborando com esse pensamento, muitos governos necessitam delinear novas estratégias de fornecimento de energia elétrica a curto e em longo prazo, em decorrência da preocupação com o aumento do consumo de eletricidade nos últimos anos. Esta apreensão justificará um planejamento mais eficaz e intransigente para essas estratégias, de maneira a abastecer as necessidades da população. Em virtude do crescimento do mercado a favor da energia eólica, já se percebe diminuição nos preços dos aerogeradores ao longo das últimas décadas, tornando-a ainda mais competitiva com outras fontes de geração devido à evolução da tecnologia, das características operacionais aplicadas à energia eólica e não somente às questões de custo. $O$ custo "zero" de seu combustível (ventos), reduzido custo de manutenção, resumido espaço de tempo necessário para sua instalação e operação, dentre outros fatores, vêm solidificando o espaço da energia eólica entre as demais fontes de energia.

\subsection{Planejamento Energético Nacional}

Desde sua origem o homem pratica o ato de planejar. Esse ato significa escolhas e muitas vezes subsidiam o ser humano no encaminhamento de suas ações e no alcance de resultados almejados, e, dessa forma orienta um fim. Nesse sentido, Engels (1896) estabeleceu uma nítida relação entre a capacidade de raciocínio do homem e sua habilidade de intervir no meio ambiente de modo planejado, executando operações, cada vez mais, complexas com o intuito de atingir objetivos cada vez mais elevados.

No campo econômico, notadamente após a Revolução Industrial, o ato de planejar ganhou espaço e ao longo dos anos, o planejamento foi sendo progressivamente sistematizado e normatizado, adquirindo peculiaridades metodológicas advindas do intenso conhecimento de aplicação nas atividades humanas. Nos tempos atuais, a atividade de planejamento é uma ferramenta largamente utilizada em diversas áreas de conhecimento, que conglomera desde as esferas públicas, como o planejamento econômico, urbano e militar, quanto o setor privado, onde o planejamento estratégico das empresas procura alocá-los em condições de vantagem sobre as concorrentes.

Ao relatar o propósito do planejamento, Faria (2000) afirma que é o alcance de objetivos e metas pré-estabelecidos, partindo-se do levantamento dos dados e informações notórias, que por sua vez, irão definir os mecanismos de atuação por parte do planejador, tendo em vista a intensidade de recursos por ele disponíveis. Dessa forma, Cima (2006) assegura que é possível 
sistematizar a atividade de planejamento em: estabelecimento de objetivos e metas a serem alcançados; diagnóstico da situação passada e atual, através de ferramentas que permitam estabelecer correlações entre as intervenções passadas e a atual situação. Consiste, portanto, na reunião da maior quantidade de dados possível, com a finalidade de examinar o problema em todos os seus aspectos e estabelecimento de políticas, que determinam o que fazer e como fazer, para se atingir os objetivos.

Ao adentrar na perspectiva global do planejamento no âmbito econômico, Cima (2006), contextualiza que a regra é assegurar a consistência entre a oferta e a demanda de bens em todos os setores. Ressalva que como se pressupõe, no caso do planejamento econômico, que este mecanismo de equilíbrio entre os níveis de oferta e demanda deve ocorrer.

Prevê-se inicialmente um crescimento da demanda agregada por bens e serviços dentro das hipóteses do plano e, em seguida, dentro da lógica sequencial do planejamento econômico, a demanda é estimulada segundo o padrão de desenvolvimento escolhido e sua evolução é estimada, de forma que o próximo passo seja garantir que o crescimento da oferta ocorra de forma compatível e ao menor custo econômico (CIMA, 2006).

No âmbito do planejamento energético tradicional essa lógica é válida e acompanha a mesma coerência do planejamento econômico, dada a estreita relação entre o consumo de energia e o desenvolvimento econômico. Contudo, a flexibilidade dessa relação, em consequência da ruptura ocasionada pelos choques do petróleo, conduziu a um questionamento do mecanismo tradicional e deu passagem para um novo paradigma de análise dos padrões de utilização da energia.

Nas pegadas desse enfoque, percebe-se que até a crise do petróleo ocorrida na década de 1970, o ato de planejar o setor energético possuía muitas singularidades com o planejamento econômico então praticado: atender a demanda a um custo mínimo. A variável custo, no planejamento tradicional, limitava-se às circunscrições financeiras de oferta de energia, não sendo contemplado, até então, nenhum aspecto de ordem social ou ambiental relacionado com a implementação da alternativa de suprimento. Outrossim, a dinâmica de substituição dessas fontes não era ponderada, resultando em uma rigidez que servia de justificativa para setorialização do planejamento (ARAÚJO, 1988; BAJAY, 2004, CIMA, 2006).

A preocupação principal do planejamento energético consistia na otimização setorial do atendimento da demanda energética que, por sua vez, era valorizada a partir de projeções empíricas em face do crescimento econômico (CIMA, 2006). O que era preocupante se espelhava nos modelos de oferta de energia, voltada à melhor forma de atender a demanda de energia, principal preocupação dos tomadores de decisão. No entanto, sua aplicação se limitava a estudos setoriais e independentes, baseados em um planejamento não integrado, que muitas vezes, levavam a conflitos de objetivos e sub-otimização inter-setorial (CODONI; PARK; RAMANI, 1985; CIMA, 2006).

Atualmente, três décadas após a grave crise do petróleo, o planejamento energético adotado pela administração federal demonstra que os preceitos da linha tradicional continuam sendo seguidos. O Plano Decenal de Expansão da Energia, produzido pelo Ministério de Minas e Energia, é um dos exemplos de planejamento direcionado por metodologias de desenvolvimento tradicional. O documento, que delineia as metas energéticas para o setor no período 2010-2019, prevê, em sua última versão, a expansão de termelétricas a combustíveis fósseis e o crescimento 
de em torno de $100 \%$ das emissões do setor elétrico nesse período. Ainda que o plano preveja a expansão de fontes renováveis como biomassa e eólica, os resultados vão de encontro às propostas de minimização de gases de efeito estufa contidas no Plano Nacional de Mudanças Climáticas e as mais recentes metas de redução de emissões de gases causadores do efeito estufa - entre 36 e 38\% - levadas a Conferência das Partes 15, em Copenhague (BAITELO, 2011).

O atual modelo de planejamento do setor elétrico no Brasil foi estabelecido em 2004, que possui como principal instrumento de expansão a oferta e a realização de leilões. O objetivo principal dos leilões é o de garantir que a oferta se amplie de forma a atender ao crescimento da demanda com o menor custo de geração possível, em linha com a precisão de se garantir a modicidade tarifária, um dos pilares do marco regulatório do setor elétrico brasileiro.

Um exemplo de Leilão é o caso do de Energia de Reserva específico para energia eólica realizado em Dezembro de 2009. Esse Leilão deve ser entendido como um marco inicial de uma nova fase para a energia eólica. O seu resultado refletiu o êxito de uma política energética geral que vem se ajustando na direção de buscar promover a ampliação das fontes renováveis na matriz. Contudo, O primeiro leilão de fontes alternativas ocorreu em maio de 2007, objetivando contratar projetos de geração a partir de biomassa, ventos e $\mathrm{PCH}^{\prime}$ s que iniciassem a entrega de energia em 10 de janeiro de 2010, conforme descrito em seu Edital (ANEEL, 2011).

Entre os tipos de leilões usados, destaca-se o leilão genérico que permite a competição, no mesmo certame, de projetos que utilizam diferentes fontes de energia. Esta formatação da contratação de energia por leilões genéricos é conflitante com o planejamento do setor elétrico. A partir do momento em que o leilão é genérico e não se sabe, a priori, qual a tipologia dos empreendimentos vencedores, logo pode surgir um elemento de contradição entre o resultado do leilão e o planejamento elétrico definido e formulado ex ante.

Neste sentido, o planejamento do setor elétrico brasileiro adquire a formatação de um planejamento ex-post aos resultados dos leilões genéricos, tendo em vista que são os resultados dos leilões genéricos que definem a estrutura futura da matriz. Esta parece ser uma contradição com o conceito de planejamento que, por definição, é algo ex-ante.

Contudo, num enfoque de longo prazo, o Planejamento Energético na esfera federal é fortemente criticado por organizações da sociedade civil e instituições acadêmicas, ilustrada em exemplos de cenários energéticos elaborados em parceria. O cenário - ( $r$ ) evolução energética do Greenpeace apresenta que é possível manter, em num horizonte de longo prazo, a participação de $92 \%$ energias renováveis, na matriz elétrica congregada a minimização de $26 \%$ da projeção do consumo de eletricidade (BAITELO, 2011). O cenário prevê também a diversificação entre as fontes eólica, solar, biomassa e hidrelétricas (em pequenas centrais), aproveitadas em diferentes tecnologias. A geração elétrica a carvão, óleo diesel e nuclear é totalmente excluída da projeção para o ano de 2050.

Ressalve-se que a dialética da diversificação de fontes de energia é uma justificativa adequada por diferentes razões. Primeiramente, pela disponibilidade de fontes. O país tem potencial para ampliar fontes não renováveis, como petróleo, gás natural, carvão, dentre outras. Mas também tem forte potencial para algumas energias renováveis, como eólica, solar, biomassa, hidrogênio e energia dos oceanos. Num enfoque geopolítico, é importante que um país não dependa de uma ou de poucas fontes de energia. As desordens políticas em outros países podem 
acarretar sérios contratempos ao setor energético. Todo um planejamento pode dar errado em decorrência de uma mudança no cenário internacional, o que não é incomum.

Em termos socioambientais, mostra-se basilar, pois a diversificação faz enfraquecer os impactos variados das diversas fontes. Assim, pode acontecer uma situação de uma matriz com variadas fontes, cada qual com seus problemas e riscos, porém pequenos, quando comparados ao uso intensivo de poucas fontes. A diversificação também reduz inúmeros problemas ou riscos de desabastecimento devido a sazonais ou climáticos, tais como secas, as quais podem, por exemplo, diminuir o nível de represas, acabar com safras agrícolas; ou diminuição sazonal da intensidade de ventos, etc. Pode ser ainda, uma estratégia econômica, pois, no caso de alta dos preços de um combustível pode-se optar por outro.

Quanto ao modelo de planejamento do setor elétrico brasileiro a ser seguido e adotado na perspectiva de promoção do desenvolvimento sustentável, este deve atentar para incorporação da variável ambiental, que deve ser contemplada na análise de quais os empreendimentos que devem ser inseridos na matriz elétrica brasileira. A formatação de um instrumento com base em metodologia consistente que possibilite comparar empreendimentos de fontes geração distintas, em um padrão de geração de predominância hidrelétrica é extremamente difícil, ainda mais ao se incorporar a variável ambiental. Desta forma, e por estes motivos, os leilões genéricos devem ser substituídos por leilões específicos. O planejamento deve determinar e indicar parâmetros para a participação de cada fonte de energia, buscando e convergindo para uma matriz energética ideal no longo prazo.

\subsection{Plano Nacional de Energia 2030}

O Plano Nacional de Energia 2030 (EPE, 2007) foi o primeiro planejamento de longo prazo de energia editado e publicado pela EPE. Ao lado de outro documento, chamado Matriz Energética Nacional 2030, o PNE 2030 é a principal ferramenta de planejamento de longo prazo à disposição dos gestores públicos e privados do setor. Órgãos como o Ministério de Minas e Energias (MME), a Empresa de Pesquisa Energética (EPE) e o Conselho Nacional de Política Energética (CNPE) utilizam o PNE 2030 diariamente.

O documento aborda diferentes cenários de evolução do setor energético e discute o setor elétrico em um capítulo específico, independente das fontes utilizadas.

Nessa abordagem há uma retrospectiva do cenário energético nacional em comparação com o que se prospecta para 2030. Nesse sentido, o PNE 2030 (EPE, 2007) considera que a população brasileira no ano 2030 será maior em 55 milhões de pessoas, um contingente comparável à população atual do Nordeste brasileiro ou de países como a Espanha e a França. Uma renda maior e mais bem distribuída impulsionará o consumo de energia. A demanda de energia per capita evoluirá, como indicado no estudo da EPE, dos atuais 1,2 para 2,3 toneladas equivalentes de petróleo (tep). Ainda assim será inferior ao consumo atual de países com a Bulgária, Grécia, Portugal ou África do Sul.

Quanto ao Brasil, de acordo com PNE, o país conseguirá manter um grau relativamente baixo de dependência externa de energia, custos competitivos de produção de energia e níveis de emissões de gases (um dos mais baixos do mundo) praticamente inalterados. 
Nessa visão prospectiva, a diversificação da matriz energética deixa de ser um objetivo estratégico principal, uma vez que está definitivamente incorporada à dinâmica de sua evolução. Os estudos confirmam uma clara tendência nessa direção: em 1970, apenas dois energéticos (petróleo e lenha), respondiam $78 \%$ do consumo de energia; em 2000, eram três os energéticos que explicavam $74 \%$ do consumo (além dos dois já citados, a energia hidráulica); para 2030, projeta-se uma situação em que quatro energéticos serão necessários para abranger $77 \%$ do consumo. Além do petróleo e da energia hidráulica, entram em cena a cana-de-açúcar e o gás natural, em contraponto à redução de importância da lenha. Tanto a cana-de-açúcar, quanto o gás natural passam a se constituir, respectivamente, nos mais importantes energéticos da matriz nacional depois do petróleo.

No que se refere à fonte eólica, o PNE 2030 condiciona o seu uso às seguintes premissas: a busca de soluções ambientalmente sustentáveis para a matriz energética brasileira e a minimização do custo da energia para o consumidor final (EPE, 2007). Contudo, apesar de o Plano assumir um ganho de competitividade em relação à energia eólica a longo prazo, sobretudo em decorrência do seu potencial promissor e interesse de fabricantes na época, a prioridade do Plano em relação às fontes renováveis ainda é a biomassa de cana, devido ao seu menor custo de geração. Apesar da perspectiva que a fonte hidráulica permaneça sendo a principal fonte de geração e que as fontes alternativas também tenham crescimento significativo, o Plano prevê uma representatividade maior da geração térmica, podendo, até, vir a funcionar na base do sistema (NOGUEIRA, 2011).

Quanto a suprir a demanda de energia prevista no Plano, que pode chegar a $1.243,8 \mathrm{MW}$ em 2030 no cenário de maior crescimento, o Plano prevê ações no sentido de gerenciar a demanda e reduzir o consumo através de conservação e eficiência, além de expandir a oferta de eletricidade. Quanto à expansão da oferta, utilizou-se o modelo de programação linear e o critério adotado foi o de mínimo custo total de expansão do sistema no intervalo de tempo considerado de forma a assegurar suprimento dentro de critérios de confiabilidade pré-estabelecidos (NOGUEIRA, 2011).

Santos e Souza (2011) ao proferirem análise dos principais procedimentos e conteúdo do PNE 2030 identifica uma estrutura de planejamento forte em modelos econômicos, porém, fraca em modelos ecológicos, de forma que, sob o discurso da definição de uma estratégia de expansão da oferta de energia, na visão de desenvolvimento sustentável do país, o PNE 2030, de fato, não insere a variável ambiental no processo decisório. Os estudos de inventário e diagnóstico, por exemplo, apesar de admitirem a existência de alguns conflitos potenciais com relação às unidades de conservação, terras indígenas, quilombos, reservas extrativistas e às políticas de desenvolvimento sustentável para as regiões com potencial hídrico, limitaram-se à realização de descrições genéricas sobre tais assuntos, de forma que, não se pode verificar se essas informações foram ou não ponderadas na tomada de decisão. No PNE 2030, também não se identificam procedimentos de orientação à tomada de decisão sobre a eliminação de alternativas de ampliação da oferta de energia por motivos ambientais. O PNE 2030 refere-se à participação popular de maneira tardia ao processo decisório, justificando as decisões depois de tomadas, sem permitir a participação no ato da construção do plano.

Os procedimentos de articulação entre as vertentes institucional, técnico-científica e comunitária empregados não viabilizaram a compatibilização entre objetivos estratégicos e de interesse nacional, de sustentabilidade e proteção ao meio ambiente (SANTOS; SOUZA, 2011). 
Goldemberg (2008) ao falar acerca do PNE 2030 compatibiliza da mesma visão critica de Santos e Sousa (2011) e ainda acrescenta que, as declarações ingênuas de que o Brasil não tinha planejamento energético e agora tem, são um reflexo de ignorância ou de arrogância. O que há de inadequado nesse procedimento é que ele ignora ou lhes dá importância menor dois fatores que se mostraram de fundamental importância em outros países. O primeiro deles é a ideia de que o aumento do bem-estar da população não é medido somente pelo crescimento econômico, mas pelo Índice de Desenvolvimento Humano (IDH), que leva em consideração não só renda per capita, mas também educação e saúde. O IDH do Brasil tem melhorado não só pelo crescimento da renda, mas pelas melhorias em atendimento social. Por essa razão, basta um cálculo simples para mostrar que não é preciso triplicar o consumo de energia do Brasil para atingir o nível de conforto da Espanha ou da Itália, mas apenas dobrar esse consumo. Isso significa menos obras, mas mais investimentos em educação e saúde, que consomem menos energia. O segundo é que a utilização mais eficiente da energia pode conduzir aos mesmos efeitos que se desejam, com menos consumo.

Conseguinte essas elucidações, percebe-se que a abordagem da variável ambiental utilizada na visão do PNE 2030 é precária para ajustar adequadamente o desenvolvimento das atividades do setor e a proteção ambiental. Trata-se a variável ambiental como um fator de restrição ou impedimento para a expansão da oferta de energia, é indicado os condicionantes socioambientais para cada fonte/empreendimento energético (SANTOS; SOUZA, 2011).

Nesse sentido, não se verificam métodos de orientação à tomada de decisão acerca da supressão de alternativas de expansão da oferta de energia por motivos ambientais. Um verdadeiro Plano Nacional de Energia para 2030 deveria ter levado em consideração os fatores participação popular na construção do plano, índice de desenvolvimento humano da população, e a inserção da variável ambiental, não como uma correção de pequena importância, mas como hipóteses essenciais de trabalho. Alguns empreendedores talvez não gostem muito disso, mas o País como um todo se beneficiaria. Portanto, torna-se preciso e urgente uma reformulação do PNE 2030, para que se percorra um desenvolvimento com sustentabilidade e em longo prazo.

\section{4 À GUISA DE CONSIDERAÇÕES}

À luz das crescentes apreensões relacionadas ao meio ambiente, o enfoque do planejamento energético está incorporado nas discussões sobre políticas de desenvolvimento da maioria dos países, haja vista a inquietação global acerca dos níveis de emissões de poluentes decorrentes de um intenso consumo de combustíveis fósseis para a produção de energia e o consequente conflito à base de recursos do planeta e ao clima global.

Embasado nessa abordagem o texto procurou revelar, no perfil da matriz energética brasileira, as perspectivas e os principais desafios de um eficaz planejamento energético para a geração de energias alternativas, notadamente a energia eólica na Região Nordeste do Brasil. Isto em virtude das fontes alternativas de energias renováveis constituírem uma importante opção complementar ao atendimento do crescimento das necessidades, tendo múltiplas vantagens ambientais, dentre as quais a redução potencial dos gases responsáveis pelo efeito estufa na atmosfera.

Seguindo esse argumento, permite-se enfatizar em decorrência da abordagem teórica realizada que quando se pensa em planejamento energético nacional, o conceito mais adequado 
é o que considera a incorporação de alternativas energéticas, o que torna a questão do insumo energia bastante importante, ampla e complexa, em virtude da solução não se tratar de uma ação isolada, mas de um conjunto de ações por parte de governos, empresas e sociedade em geral.

Quanto ao atual planejamento energético nacional adotado pelo Governo Federal, demonstra-se com clareza que continuam sendo seguidos os preceitos da linha tradicional. Com isso, o desafio presente de governos e grupos de planejadores e tomadores de decisão consiste na modificação de parâmetros de avaliação econômica e social, no remodelamento de sistemas de geração e consumo e de energia e na conciliação da sustentabilidade em suas múltiplas dimensões.

Inúmeros são os instrumentos que podem ser usados para viabilizar a garantia do abastecimento energético de forma contínua e segura, muitos dos quais incompatíveis entre si e divergentes de outros objetivos atribuídos ao Estado, mais marcantemente a busca da competitividade econômica. Dessa forma, as escolhas técnicas e econômicas que conduziram, e conduzem o setor energético têm sido ao final, decisões de caráter político, muitas das quais feitas sem a real garantia de uma avaliação favorável. A história da energia mostra, de forma incontestável, que as escolhas feitas no curso do desenvolvimento do setor elétrico mundial foram, e continuam sendo, marcadas por ocorrências políticas, fruto do embate econômico, no qual o mercado mundial de energia está inserido. Nesse sentido, as atuais políticas de incentivo às fontes alternativas de energia, de eficiência energética e de extensão de acesso à luz elétrica, por exemplo, tornam-se imprescindíveis como forma de ultrapassar as barreiras e direcionar o desenvolvimento econômico sustentável, mas são insuficientes quando a sociedade não redesenha os hábitos e costumes de consumo, por exemplo.

Nem todas as fontes de energia poderão ter o seu papel num futuro próximo, notadamente, em decorrência da finitude de alguns recursos naturais. Por implicação, as pessoas necessitarão participar ativamente na construção de uma nova sociedade respaldada em sistemas energéticos do futuro, especialmente, aqueles relacionados às energias alternativas, abandonando a passividade de apenas consumidores.

Pensar em novas fontes de energia, a partir de referenciais socioambientais, significa, principalmente, pensar em evitar riscos de autodestruição e em obter-se vantagens socioambientais, mais do que vantagens econômicas. Significa também transformações na estrutura econômica, de forma semelhante com o que ocorreu em outros momentos da história, como no início da era do petróleo.

Constitui desafio de grande relevância a modificação no perfil da demanda energética, a ampliação da eficiência na produção e no uso final de energia e a transição de energias não renováveis por renováveis. Advertindo-se que as conquistas alcançadas no setor elétrico decorrem fundamentalmente da revisão do marco regulatório e institucional ocorrida há mais de oito anos, que propiciou condições favoráveis aos investimentos, como se demonstra na competitividade dos recentes leilões de geração de energias alternativas, com destaque para a eólica. Apesar do notável acréscimo, isto representa pouco em relação ao potencial eólico existente no Brasil, sobretudo na Região Nordeste, o que revela espaço para um crescimento ainda mais agressivo da capacidade eólica para os próximos anos.

Contudo, advirta-se que o alcance de uma matriz energética nacional limpa depende de ações integradas e pautadas no rigor do conceito de planejamento energético, atrelado ao desenvolvimento sustentável e às ações e políticas de sustentabilidade, pois a atribuição de que a 
matriz energética brasileira é limpa, devido ao uso de hidrelétricas, apresenta controvérsias socioeconômicas e ambientais, que podem conduzir a erros contínuos de planejamento e de políticas energéticas.

Dessa forma, a questão do eficaz planejamento energético e a defesa pela importância da inserção de fontes alternativas de energia na atual matriz energética, centraliza o debate, impulsionado pelo viés do desenvolvimento sustentável. $O$ argumento para essa assertiva reside no fato de que uma provável insuficiência de energia tem um custo elevado, podendo provocar por sua vez, a paralisação dos setores chaves da economia, estendendo-se de tal forma que pode levar a um colapso econômico.

\section{REFERÊNCIAS}

1. ABRAMOWSKI, J.; POSORSKI, R. Wind energy in developing countries. DEWI Magazine, n. 16, p. 46-53, February, 2000.

2. AGÊNCIA NACIONAL DE ENERGIA ELÉTRICA. ANEEL. Disponível em: <http://www.aneel.gov.br>. Acesso em: 29 ago. 2012.

3. AGÊNCIA NACIONAL DE ENERGIA ELÉTRICA. Brasília: ANEEL, 2011. Disponível em: <http://www.aneel.gov.br/area.cfm?idArea=671\&idPerfil=2> Acesso em: 20 jan. 2013.

4. ARAÚJO, J. L. Modelos de energia para planejamento. COPPE/UFRJ, Rio de Janeiro, RJ, 1988.

5. BAITELO, R. L. Modelo de cômputo e valoração completa de potenciais de recursos energéticos para o planejamento integrado de recursos. 2011. Tese (Doutorado). Escola Politécnica da Universidade de São Paulo. Departamento de Engenharia de Energia e Automação Elétricas.

6. BAJAY, S. V. National Energy Policy: Brasil. Encyclopedia of Energy, v. 4. Elsevier, 2004.

7. BITTENCOURT, R. M.; AMARANTE, O. C.; SCHULTZ, D. J. Estabilização sazonal da oferta de energia através da complementaridade entre os regimes hidrológico e eólico. In: Seminário nacional de produção e transmissão de energia elétrica - SNPTEE, 15, 1999. Foz do Iguaçu: anais, 1999, GLP-17.

8. BRACKMANN, R. Avaliação do potencial eólico do sul do Brasil. Centro Regional Sul de Pesquisas Espaciais - CRS/INPE-MCT, 2009.

9. CIMA, F. M. Utilização de indicadores energéticos no planejamento energético integrado. 2006. Dissertação (Mestrado). Universidade Federal do Rio de Janeiro, COPPE, Rio de Janeiro.

10. CODONI R.; PARK H.; RAMANI K. Integrated Energy Planning - A Manual. Asianand Pacific Development Centre. Kuala Lampur, 1985.

11. COMPANHIA ENERGÉTICA DE MINAS GERAIS - CEMIG. Alternativas energéticas: uma visão Cemig. Belo Horizonte: Cemig, 2012.

12. DUTRA, R. M. Propostas de políticas específicas para energia eólica no Brasil após a primeira fase do PROINFA. 2007. Tese (Doutorado). COPPE/UFRJ, D.Sc., Planejamento Energético. Universidade Federal do Rio de Janeiro, COPPE, Rio de Janeiro.

13. EMPRESA DE PESQUISA ENERGÉTICA - EPE. Plano Decenal de Expansão de Energia 2020. Rio de Janeiro, 2011. 
14. ENGELS, F. O papel do trabalho na transformação do macaco em homem. In: Neue Zelt, Alemanha, 1896.

15. EMPRESA DE PESQUISA ENERGÉTICA - EPE. Plano Nacional de Energia 2030. Rio de Janeiro, 2007.

16. FARIA, J. C. Administração: teoria e aplicações. Thomson, Rio de Janeiro, 2000.

17. FRATE, C. A. Políticas públicas para energias renováveis: fator de competitividade para eletricidade eólica e siderurgia semi-integrada. 2006. Dissertação (Mestrado). Centro de Desenvolvimento Sustentável da Universidade de Brasília, UNB, Brasília.

18. GOLDEMBERG, J. Biotechnol Biofuel, 1, 1, 2008.

19. GLOBAL WIND ENERGY COUNCIL - GWEC. Top 10 annual \& cumulative capacity. 2006. Disponível em: <http://www.gwec.net>. Acesso em: 28 set. 2010.

20. INTERNATIONAL JOURNAL ON HYDROPOWER \& DAMS [IPCC]. 2010 World Atlas \& Industry Guide. Disponível em: <INTERGOVERNMENT PANEL ON CLIMATE CHANGES. IPCC Special Report on Renewable Energy Sources and Climate Change Mitigation. 2011. Disponível em: <http://www.ipcc-wg3.de/publications/special-reports>. IPCC, 2011.

21. JUNFENG, L. et al. A study on the pricing policy of wind power in China. Brussels: GWEC, 2006.

22. MINISTÉRIO DE MINAS E ENERGIA - MME. Boletim Mensal de Energia. Mês de Referência: dezembro de 2011. MME, 2012.

23. ___ Plano Nacional de Eficiência Energética - Premissas e Diretrizes Básicas. MME, 2011.

24. _. Plano Decenal de Expansão de Energia, 2008/2017. Rio de Janeiro: EPE, 2009.

25. _._. Balanço Energético Nacional - BEN, 2005.

26. NASCIMENTO, T.; C.; MENDONÇA, A. T. B. B.; CUNHA, S. K. Inovação e sustentabilidade na produção de energia: o caso do sistema setorial de energia eólica no Brasil. Cad. EBAPE BR., v. 10, n. 3, Rio de Janeiro, Sept., 2012.

27. NOGUEIRA, L. P. Pupo. Estado atual e perspectivas futuras para a indústria eólica no Brasil. 2011. Dissertação (Mestrado). UFRJ/COPPE/Programa de Planejamento Energético, 2011.

28. REIS, L. B.; FADIGAS, E. A. A.; CARVALHO, C. E. Energia, recursos naturais e a prática do desenvolvimento sustentável. Barueri, SP. Manole, 2005.

29. SACHS, I. A revolução energética do século XXI. Estudos Avançados, v. 21, n. 59, 2007.

30. SANTOS, S. M.; SOUZA, M. P. Análise das contribuições potenciais da avaliação ambiental estratégica ao plano energético brasileiro. Eng. Sanit. Ambient., v. 16, n. 4, Rio de Janeiro, Oct./Dec., 2011.

31. SWISHER, J.; JANNUZZI, G.; REDLINGER, R. Tools and methods for integrating resource planning. UNEP, Denmark, 1997.

32. TOLMASQUIM, M. T.; GUERREIRO, A.; GORINI, R. Matriz energética brasileira. Novos Estudos, n. 79, nov. 2007.

33. TOLMASQUIM, M. T. Perspectivas e planejamento do setor energético no Brasil. Estudos Avançados, v. 26, n. 74, 2012. 